\title{
Assessing the distribution and conservation status of a long-horned beetle with species distribution models
}

\author{
Daniel P. Silva ${ }^{1}$ - Albert G. Aguiar $^{2} \cdot$ Juliana Simião-Ferreira $^{3}$
}

Received: 2 February 2016/Accepted: 1 July 2016/Published online: 7 July 2016

(C) Springer International Publishing Switzerland 2016

\begin{abstract}
Data shortfalls on species distribution affect species differently, but it is frequent among insects. Species distribution models (SDMs) are important tools to fill biogeographic deficits and provide support for practical conservation actions, particularly for cryptic or hard to survey species. We employed SDMs to evaluate one such species, the long-horned beetle (Macrodontia cervicornis), listed as 'vulnerable' in the IUCN's Red List of Threatened Species. Given new distributional data for this species, we applied three different SDMs to: (1) provide the first assessment of this species' distribution and potential dispersal routes; (2) evaluate the effectiveness of the current South American protected areas system for its conservation; and (3) discuss its potential distribution, as well as historical, biogeographical, and taxonomic issues related to it. Our models reached fair True Skilled Statistics values (TSS > 0.5), with the core area for M. cervicornis located in the Amazon forest, although suitable areas were also
\end{abstract}

Electronic supplementary material The online version of this article (doi:10.1007/s10841-016-9892-8) contains supplementary material, which is available to authorized users.

Daniel P. Silva

daniel.paivasilva@gmail.com

1 Departamento de Ciências Biológicas, Instituto Federal Goiano, Rodovia Geraldo Silva Nascimento, KM 2,5, Zona Rural, CEP 75790-000, Urutaí, GO, Brazil

2 Institute of Biosciences, Languages and Exact Sciences, Ecology Department, São Paulo State University (UNESP), Cristóvão Colombo, St., 2265, Jd. Nazareth, São José Do Rio Preto, SP 15054-000, Brazil

3 Universidade Estadual de Goiás, Unidade de Ciências Exatas e Tecnológicas, BR 153, No 3105 Fazenda Barreiro do Meio, Campus Henrique Santillo, CEP 75132400, Anápolis, GO, Brazil predicted along the Atlantic forest. Areas in the dry diagonal South American corridor (dry biomes of Cerrado, Caatinga, and Pampas) in South America were not predicted as suitable. The preference of M. cervicornis for humid areas with high temperatures may guarantee a better physiological control for dehydration, considering that large insects are more affected by water loss. In general, approximately $15 \%$ of the distribution of M. cervicornis is in humid protected areas. The disconnected distribution of the long-horned beetle may be an indication of the existence of cryptic species under the same classification. We suggest that similar studies with other insect groups (e.g. butterflies, bees) should be conducted to properly assess their distributions, conservation status, and responses to hot-humid gradients throughout South America.

Keywords Ecological niche - South American dry diagonal · Atlantic forest · Amazon forest - Brazil · South America

\section{Introduction}

Among all biological data shortfalls concerning species biological knowledge (e.g. Hutchinsonian, Prestonian, Darwinian, Linnean; Whittaker et al. 2005; Cardoso et al. 2011; Diniz-Filho et al. 2013; Hortal et al. 2015), the Wallacean shortfall - the lack of proper knowledge on species distribution (Whittaker et al. 2005) —is the largest knowledge gap hindering effective conservation practices at large geographic scales, since species distributions are the main variable considered in analyses for practical conservation actions (Myers et al. 2000; Brooks et al. 2006). Biological data shortfalls may affect all species, but in different manners based upon a species' detectability. 
For instance, species distributions for vertebrates are far more common compared to invertebrates (Diniz-Filho et al. 2010; Newbold 2010; Pyke and Ehrlich 2010; Cardoso et al. 2011). Yet, even for well-known insect groups (i.e. butterflies, ants, dragonflies, bees), the lack of distributional knowledge is common (Diniz-Filho et al. 2010; Cardoso et al. 2011).

Despite the ecosystemic and economic importance of insects (e.g. Losey and Vaughan 2006), and also their striking biological diversity (Mora et al. 2011), these "little things that run the world" (Wilson 1987) have been neglected in practical conservation planning for a long time, especially given the lack of knowledge on their distribution ranges (Diniz-Filho et al. 2010; Cardoso et al. 2011). Nonetheless, given recent improvements in biodiversity data availability (Graham et al. 2004; Newbold 2010; Pyke and Ehrlich 2010), and the use of species distribution models (SDMs hereafter), more and more insect species are being considered in the framework of Conservation Biogeography (Whittaker et al. 2005).

Although species distribution is determined by the intersection of abiotic and biotic conditions, in addition to reachable environments by the species itself (BAM diagrams; Soberón and Peterson 2005; Soberón 2007), the biotic components of the niche are usually underrepresented in SDMs. As a consequence, there is a great debate in the related literature as to whether these techniques correctly represent the spatial projection of a species range (Doko et al. 2011; McInerny and Etienne 2012a, b, c; Virkkala et al. 2013; Russo et al. 2014). Still, SDMs are able to fill knowledge gaps regarding species distribution and are an important tools for the application of practical conservation actions involving species with limited distribution information (Almeida et al. 2010; Bosso et al. 2013; Silva et al. 2013).

These techniques are increasingly being used with insect species to (1) determine potential distributions upon the discovery of new occurrences and areas for future samplings (Almeida et al. 2010; Serra et al. 2012; Bosso et al. 2013; Silva et al. 2013; 2014a); (2) indicate important areas for the implementation of new protected areas (Nóbrega and De Marco 2011; Bosso et al. 2013; Russo et al. 2015); (3) predict the potential invasion of exotic species (Da Mata et al. 2010; Silva et al. 2014a); (4) assess the potential effects of future scenarios of climate changes on the distribution of insect species (Giannini et al. 2012; Ferro et al. 2014; Martins et al. 2015); and (5) understand insect species diversification patterns (Silva et al. 2014b). Considering the worldwide rising concerns on biodiversity loss (Dirzo et al. 2014), studies evaluating insect species potential distribution are important to prioritize areas for new populations and conservation efforts, likewise to support practical conservation decisions and assure future protection of the focal species (Guisan et al. 2013).
The large-bodied beetles from the genus Macrodontia occur all along Central and South America, from Guatemala to Argentina. Macrodontia cervicornis Linnaeus, 1758 (Coleoptera: Cerambycidae; Fig. 1a) has reported occurrences from Colombia, Ecuador, Peru, Bolivia, in both Guianas, and Brazil. Its larvae ( $\sim 21 \mathrm{~cm}$ long) develop within the bark of dead or dying softwood trees for up to 10 years, whereas the adults only live for the few months needed to reproduce. This species is large (up to $17 \mathrm{~cm}$ in body length), with unique elytral color patterns and large mandibles which make them valuable to the souvenir trade, an increasing exploitive practice that may eventually threaten this species. For these biological features and anthropogenic pressures, M. cervicornis is currently listed as "Vulnerable" on IUCN's Red List of Threatened Species (IUCN 2006). Considering the global concern of species protection and global efforts to protect at least $17 \%$ of the continental surface of the planet (COP10-Convention on Biological Diversity; Mittermeier et al. 2010), and considering that M. cervicornis is a vulnerable species, it is critical to determine whether a similar portion of its potential habitat is covered by the current South American protected areas system.

Within this context, our aims in this study were threefold, to: (1) estimate the potential range of $M$. cervicornis, indicating the potential areas for its dispersal in South America; (2) evaluate the effectiveness of different SDMs algorithms on detecting a new occurrence of $M$. cervicornis sampled by one of the authors of this manuscript (A.G. Aguiar; Fig. 1a); and (3) discuss priority areas for further studies and the implementation of practical conservation actions for the protection of $M$. cervicornis. In addition, historical/biogeographical, taxonomic and physiological determinants of the known distribution of this species were reviewed throughout the study.

\section{Methods}

\section{Macrodontia cervicornis occurrence data}

The new occurrence data was obtained from Guaraqueçaba, state of Paraná, Southern Brazil (the yellow star in Fig. 1b), and was complemented with occurrence data for $M$. cervicornis obtained from online sources [CRIA's SpeciesLink (http://www.splink.org.br), Global Biodiversity Information Facility-GBIF (http://www.gbif.org)] and literature (Escalante 1973; Salazar 2008; Martins et al. 2009; Menezes et al. 2012). Intensive searching for other occurrence records in the abovementioned data sources and related coleopterist literature was conducted using ISI Web of Science (http://www.webofscience.com), Google Scholar (http://www.scholar.google.com) and SciELO (http:// 
Fig. 1 Overall information on M. cervicornis. a The specimen sampled in Guaraqueçaba, state of Paraná, Brazil (photo rights: A.G. Aguiar). b The 31 unique occurrences for M. cervicornis obtained from all surveyed research papers and online databases (white circles) and the new occurrence for $M$. cervicornis (yellow star) are shown. The grey gradient in Fig. $1 \mathrm{~b}$ is related to the altitude, where darker colors refer to higher areas. (Color figure online)

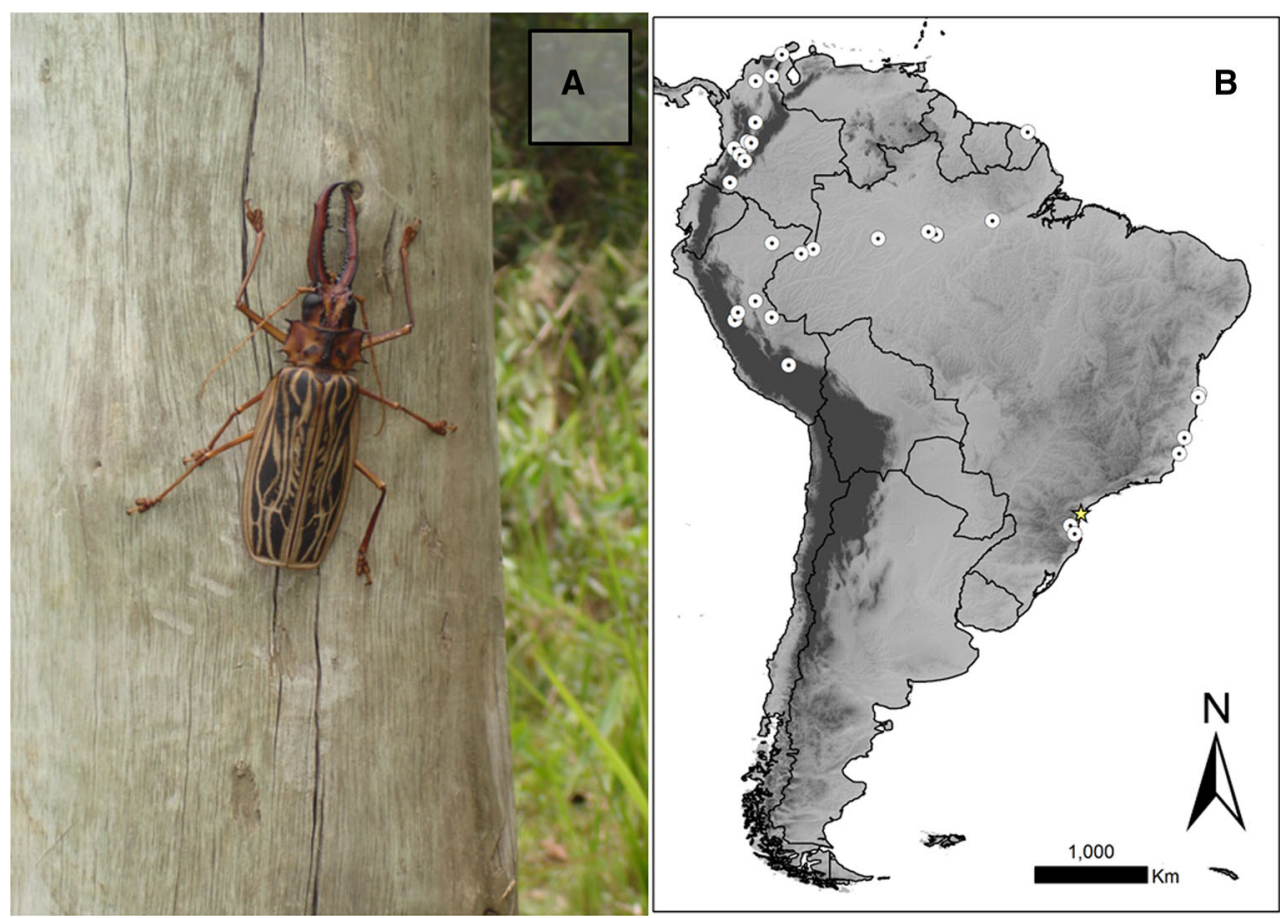

www.scielo.org) databases. In these databases, we identified other 31 occurrences from the literature (white circles in Fig. 1b) for M. cervicornis from Colombia $(n=11)$, Peru $(n=6)$, French Guiana $(n=1)$, and Brazil $(n=13)$. For the records lacking exact georeferenced information, we used Google Earth (Google Inc. 2015) to obtain city center coordinates as surrogate localities for the sampling sites of M. cervicornis. Therefore, with the new Guaraqueçaba occurrence, we identified 32 species occurrences, all of which are available in the Supplementary Materials. Based on the spatial resolution of our environmental variables ( $\sim 4 \mathrm{~km}$ at the Equator; see below), we filtered the occurrences we obtained and considered them to be spatially unique/independent ones.

\section{Environmental data, algorithms, and modeling procedures}

The environmental data used in this study follows that applied by Silva et al. (2014a), in which all of the 19 climatic variables from WorldClim (http://www.worldclim. org/; Hijmans et al. 2005) were used as input variables in a Principal Components Analysis (PCA hereafter). From the resulting 19 orthogonal Principal Components (PCs hereafter), the first seven PCs ( $\sim 98 \%$ of the original climatic variation) were used as the new predictor variables of the distribution of $M$. cervicornis. Methods to reduce the dimensionality of the predictor variables are advisable to avoid model overfitting that may cause unreliable species distributions (Jiménez-Valverde et al. 2011). The models were trained with a spatial resolution of 2.5 arc-min $\left(0.041^{\circ} \approx 4 \mathrm{~km}\right)$ and using the whole South American continent as the study extent.

Different methods of SDMs are naturally variable (Elith et al. 2006; Araújo and New 2007; Diniz-Filho et al. 2009) and by using the same occurrence data and climatic variables, different distribution models may be obtained. Therefore, we used three different methods [Maximum Entropy (Phillips et al. 2006; Phillips and Dudík 2008), Support Vector Machines (SVM; Schölkopf et al. 2001; Tax and Duin 2004), and Genetic Algorithm for Rule-set Prediction with best subsets (GARP; Stockwell and Peters 1999)] in our modeling procedures. All algorithms we used are considered as artificial intelligence algorithms, which are generally complex and tend to better predict the modelled species' known occurrences with better success than envelope or statistical algorithms (Rangel and Loyola 2012). The Maximum Entropy is a machine-learning method based on presence-background data that produces reliable distribution predictions for target species, especially for those with small amounts of occurrences (Hernandez et al. 2006; Pearson et al. 2007). The Genetic Algorithm for Rule set Production (GARP) is a non-deterministic modeling algorithms that uses random sets of mathematical rules as limiting environmental conditions determining a given species distribution (Stockwell and Peters 1999). The Support Vector Machines (SVM) is also a machine-learning algorithm from the generalized linear classifiers that minimizes structural risk and dimension to find reasonable alternatives between species adaptability and complexity, producing the most probable distributions 
with limited amounts of occurrences (Schölkopf et al. 2001; Tax and Duin 2004; Duan et al. 2014).

Maximum Entropy is implemented in MaxEnt 3.3.3.k (Phillips et al. 2006; Phillips and Dudík 2008) and all default settings were activated except for "product features", "threshold features", "hinge features", and "auto features", the so-called MaxEnt LQ (Anderson and Gonzalez 2011; Elith et al. 2011; Souza and De Marco 2014). Both SVM and GARP are implemented in openModeller Desktop v.1.1.0 (Muñoz et al. 2011), for which we used the default settings of these algorithms generally used in this software. Pseudo-absences and background data were randomly generated throughout the whole study's extent.

We jackknifed the occurrences of M. cervicornis creating $n$ subsets of $n-1$ occurrences as input for the distribution modeling algorithms combined with the climatic variables. In the first modeling round, the new occurrence data was not included in the models. Each one of these subsets was used to generate the distribution of the species and to evaluate the resulting distributions. We used the threshold that maximizes both omission and commission errors to cut the suitability matrices into presence/absence and determine the distributions for M. cervicornis in each algorithm/training subset we used (Liu et al. 2005, 2011). We applied the True Skilled Statistics (TSS; Allouche et al. 2006) to evaluate the performance of the models, which is a threshold-dependent statistic that varies from -1 to +1 . Negative values and those near zero are no better random distributions while values near +1 represent a perfect fit between the known distribution of the focal species and that predicted by the SDMs. Fair models usually reach TSS values around 0.5. After all these steps, we included the new occurrence data for $M$. cervicornis in the second modeling run and produced its distribution again.

We used the summed distribution of all M. cervicornis' distributions obtained with the different algorithms obtained in the second run to represent its final distribution (a progressive scenario). Later, using this map, we assessed the coverage of the current system of protected areas in South America (categories I to IV $\approx$ strict reserves), from IUCN's World Database on Protected Areas website (http://www.protectedplanet.net/), using a gap-analysis framework (e.g. Rodrigues et al. 2004; Nóbrega and De Marco 2011). We also produced a more restrictive scenario to evaluate the coverage of the current protected areas reserve system on protecting $M$. cervicornis. In this scenario, only areas that were predicted as suitable by all three algorithms in a strict consensus were classified as presence, while those predicted by only two or even one algorithm was considered as absences of $M$. cervicornis. A summary of all methods employed in the study is depicted in Fig. 2.
Finally, given the gathered occurrences for M. cervicornis, careful considerations on spatial autocorrelation (SAC hereon) are needed to be addressed. SAC is known to cause pervasive effects upon the results obtained with the methods employed with SDMs (Veloz 2009; Miller 2012; KramerSchadt et al. 2013; Record et al. 2013; Diniz-Filho et al. 2016). While dealing with autocorrelation of a species' occurrences, environmental autocorrelation is also an important characteristic to be considered in SDMs, and has been shown to significantly increase predictability of the modelling algorithms if properly controlled for (i.e. Varela et al. 2014; de Oliveira et al. 2014). Nonetheless, here we are dealing with a rare insect species, and previous studies from these poorly-sampled areas have already shown that every sampled occurrence available matters, being capable significantly improving in the distribution predictions for the target species (see Almeida et al. 2010; Silva et al. 2013 for some examples on how a few additional occurrences are important for these methods). Therefore, given this sampling bias and general lack of entomological knowledge in biodiverse Neotropical areas (Diniz-Filho et al. 2010; Newbold 2010; Pyke and Ehrlich 2010), here we did not control for $\mathrm{SAC}$ at first. Nonetheless, while considering the more restrictive scenarios, where only the strict consensus for the species is used, we believe the pervasive effects of SAC were controlled for.

\section{Results}

In the first modeling run, the distribution models for $M$. cervicornis attained fair TSS values $(0.585 \pm 0.078$; mean \pm standard deviation) and an average omission rate of $13.612 \% \pm 6.548$ ) with respect to the ROC threshold. SVM reached the highest average TSS values, followed by MaxEnt, and GARP (Table 1). In the first modeling run, for both GARP and MaxEnt, all of the $n-1$ subsets of M. cervicornis occurrences failed to predict its new occurrence in Southern Brazil. SVM was able to predict the new occurrence in nearly $50 \%$ of the $n-1$ occurrences subsets (Fig. 3). In the second modeling run, this pattern was similar to that encountered in the first run and only SVM was able to predict the new occurrence, although GARP also showed suitable areas near the new occurrence (Fig. 4).

All algorithms predicted that M. cervicornis has the core of its distribution within the Amazon, whereas suitable areas also occur in some portions of the northeastern Atlantic Forest, along the Brazilian east coast (Figs. 3 and 4). All algorithms predicted the absence of $M$. cervicornis in the Caatinga biome in northeastern Brazil, although there were some areas predicted as suitable. Additionally, the South American diagonal corridor of dry biomes, comprising the 


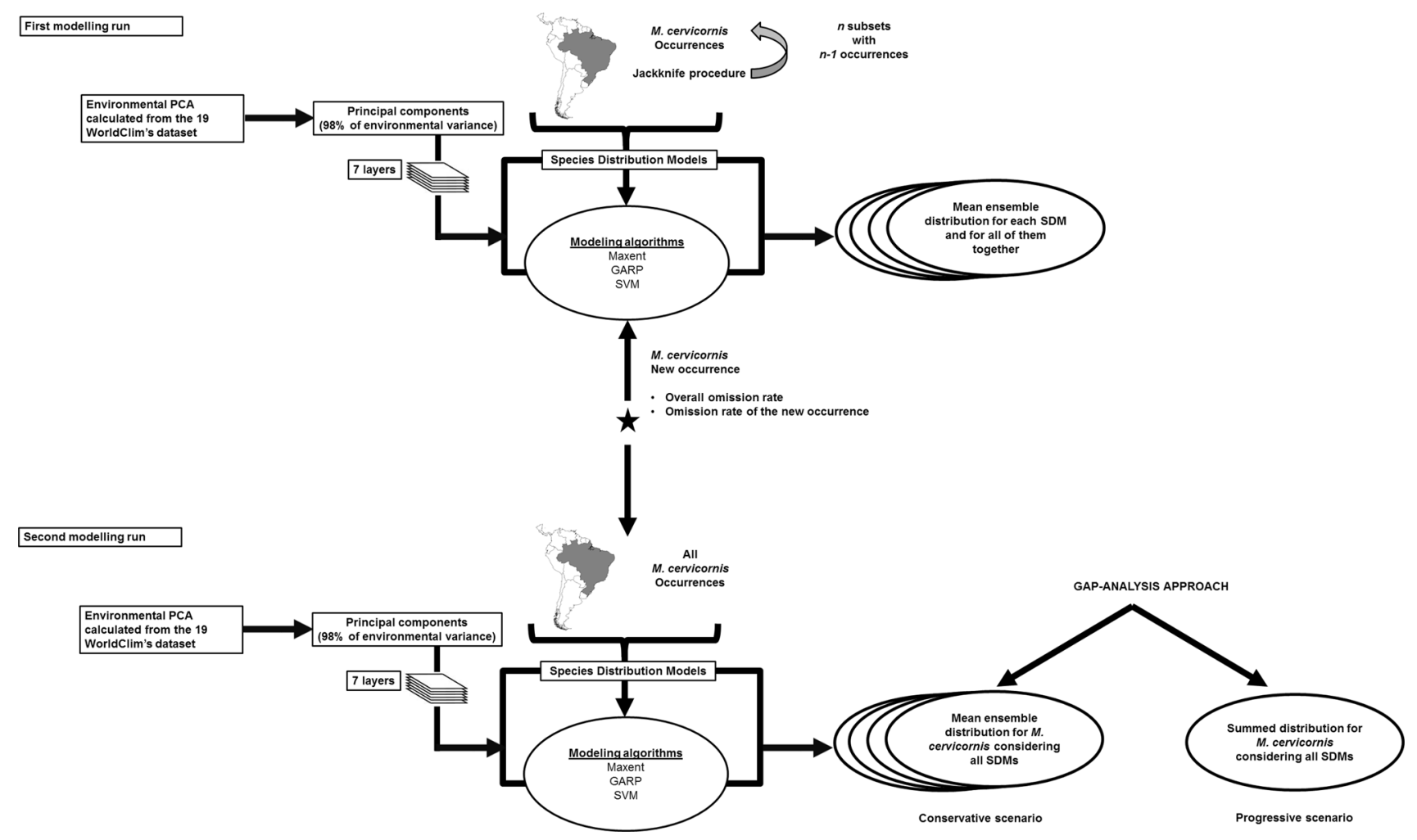

Fig. 2 Summary of all methods employed in the study

Caatinga (in northeastern Brazil), the Cerrado Savanna (central Brazil), and the Chaco (central-south South America, covering Brazil, Argentina, and Paraguay) was not indicated as suitable for the long-horned beetle. However, some portions near the Chaco region in southern Brazil were predicted as suitable for the species. Additionally, M. cervicornis was not predicted in arid regions of northwestern Venezuela and northern Colombia.

Considering the progressive conservation scenario, approximately $15.74 \%$ of $M$. cervicornis's distribution is protected by the current South American reserve system (Fig. 5a). In the more restrictive scenario for the species' protection, considering only the strict consensus for $M$. cervicornis, the percentage of protected areas was similar to the progressive scenario: $\sim 15.53 \%$ (Fig. $5 b$ ).

\section{Discussion}

According to our results, the suitable areas for $M$. cervicorinis are in core regions from the Amazon Forest and in some portions of the Brazilian Atlantic Forest. Most of the potential distributions we ran for $M$. cervicornis did not predict the new occurrence of $M$. cervicornis as suitable. Additionally, the majority of the models showed poor predictions for this species in the South American dry diagonal area, the corridor formed by the dry South American biomes of Cerrado, Caatinga, and Pampas. Despite the potential anthropogenic pressure upon $M$. cervicornis, based on the potential distribution obtained from the SDMs and the current South American reserve system, this species is relatively protected, considering the COP10's aims of protection of $17 \%$ of world's continental areas up-to 2020 (Mittermeier et al. 2010).

The lack of predicted occurrences in the South American dry diagonal corridor was a consistent pattern of all models, even though different types of SDMs are known to produce contrasting results due to their different built-in methods and correlative statistics (Barry and Elith 2006; Diniz-Filho et al. 2009; Rocchini et al. 2011), especially in the Caatinga, Cerrado, and Pampas biomes. These South American biomes are naturally dry (Ab'Saber 1977; Veloso et al. 1991; Sampaio 1995) with ubiquitous vegetation physiognomies that separate the two largest forest formations in the continent: Amazon and Atlantic rainforests, both of which were predicted as suitable for $M$. cervicornis. Given the potential distribution obtained here, the known occurrences for this species, and the existence of the dry diagonal corridor in South America, what are most likely to be the main determinants of the modeled and known distribution patterns we observed for M. cervicornis? 
Table 1 Summary of the results obtained with each method while predicting the potential distribution of $M$. cervicornis in South America. SD: Standard deviation

\begin{tabular}{lll}
\hline Algorithm & TSS $( \pm$ SD $)$ & Omission rate $( \pm$ SD $)$ \\
\hline GARP & $0.503( \pm 0.087)$ & $16.33 \%( \pm 8.929 \%)$ \\
MaxEnt & $0.564( \pm 0.004)$ & $14.77 \%( \pm 3.886 \%)$ \\
SVM & $0.673( \pm 0.055)$ & $12.79 \%( \pm 5.492 \%)$ \\
\hline
\end{tabular}

The water loss of $M$. cervicornis to the environment may be the main explanation for the lack of suitable areas predicted in the dry diagonal corridor. Dehydration/desiccation is an important issue for insects (Chown and Terblanche 2006). Although larger species are more resilient to the effects of water loss than smaller ones, even they may be impaired in environments with high temperature and low humidity, such as those found in the dry corridor. Consequently, the lack of suitable potential habitats for $M$. cervicornis in this area was expected. Although GARP predicted some humid areas potentially reachable by $M$. cervicornis in central Brazil (within the Brazilian Pantanal), the natural climatic seasonality of this biome may discourage the occurrence of the species. Consequently, the potential dispersal routes for $M$. cervicornis from the Amazonian forest to the Atlantic one (and vice versa) need to be discussed.

The dispersal of $M$. cervicornis could take place via gallery forests within the Cerrado biome, a vegetation type already proven to serve as a dispersal route for Amazonian and Atlantic species, from several different biological groups (Redford and da Fonseca 1986; Brown 1987, 1992; Silva 1996; Méio et al. 2003; Aguiar and Melo 2007; Silva et al. 2013). The lack of suitability for M. cervicornis in Cerrado itself rules out its vegetation physiognomies as a viable dispersal route. Yet, the high suitability of coastal areas in northeastern Brazil, predicted by some occurrence subsets of $M$. cervicornis (see Figs. 3 and 4), brings up the question as to whether this species uses the dry corridor to disperse along the Brazilian East Coast. Dispersal routes for species inhabiting Amazonian areas and the Atlantic Forest through the Atlantic shores have already been raised in the biogeographic literature of South America before (De Oliveira et al. 1999). We believe that for such a largebodied species as $M$. cervicornis, dispersal near humid areas are more likely than through areas within the dry corridor in the continent. Yet, such a hypothesis remains to be better evaluated for this species with the concomitant use of past distribution predictions using SDMs and investigation on $M$. cervicornis' genetic profile, and also phylogeography studies.

In light of our results, a few notes should be stressed. The first is in regards to the availability of entomological data in the tropics. Macrodontia cervicornis is a large species and, most likely, there are certainly many more occurrence records that were sampled throughout South America than those we were able to find. For instance, one of the authors (D.P. Silva) is aware of several specimens being spotted along the Atlantic Forest biome sampled by users from a Brazilian Facebook entomological group. This (and other) social medias have already proven to be important tools to gather updated distribution information for species elsewhere, such as Argentinean burrowing owls (Cavalli et al. 2014), or citizen science projects gathering occurrence data for (native and exotic) bumblebees in Chile, such as "Salvemos Nuestro Abejorro" (Save our Bumblebee; https://salvemosnuestroabejorro.wordpress. $\mathrm{com} /$ ). Even so, much of these occurrences (either from collections or from internet discussion groups) still remain unavailable for modelers to use in studies like ours (DinizFilho et al. 2010), which certainly limits our results. For instance, the inclusion in SDMs of previously unknown
Fig. 3 Predictions for the distribution of $M$. cervicornis obtained in the first modeling run with different algorithms. The values correspond to the percentage of models that predicted a given area within each map as presence or absence for M. cervicornis [dark green $=0 \%$ of the subsets predicting $M$. cervicornis as "presence"; red $=>80 \%$ of the subsets predicting $M$. cervicornis as "absent"). The new occurrence data is depicted as a star. (Color figure online)

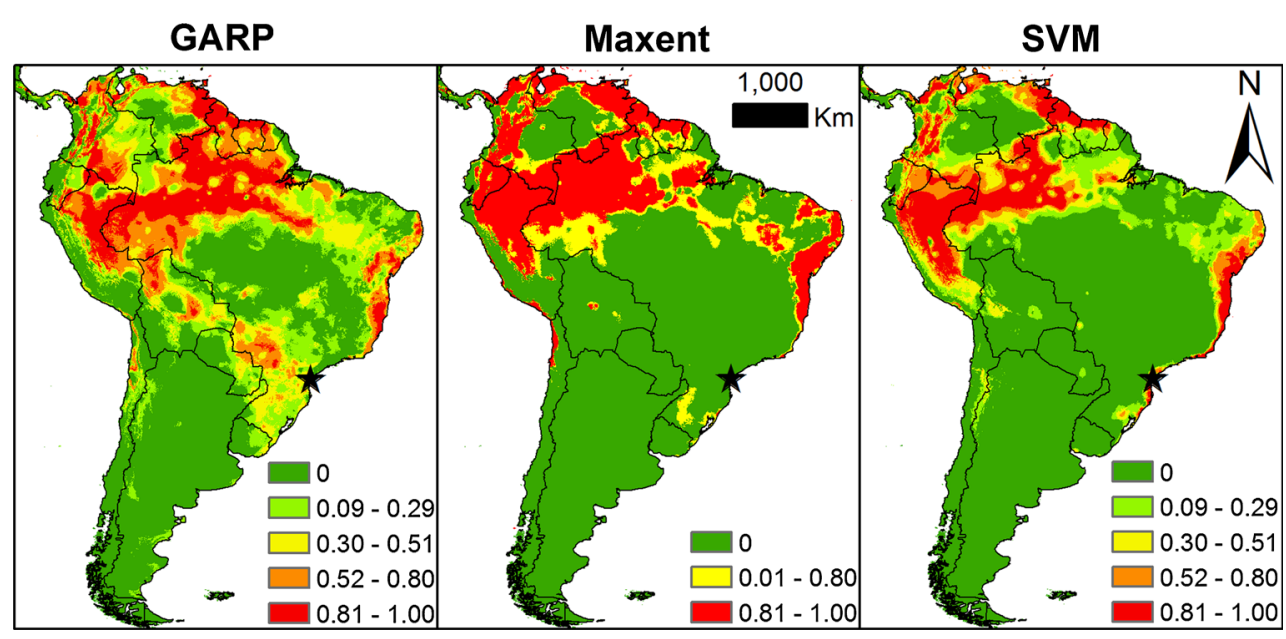


Fig. 4 Predictions for the distributions of $M$. cervicornis obtained in the second modeling run with different algorithms. The new occurrence data is depicted as a star. (Color figure online)

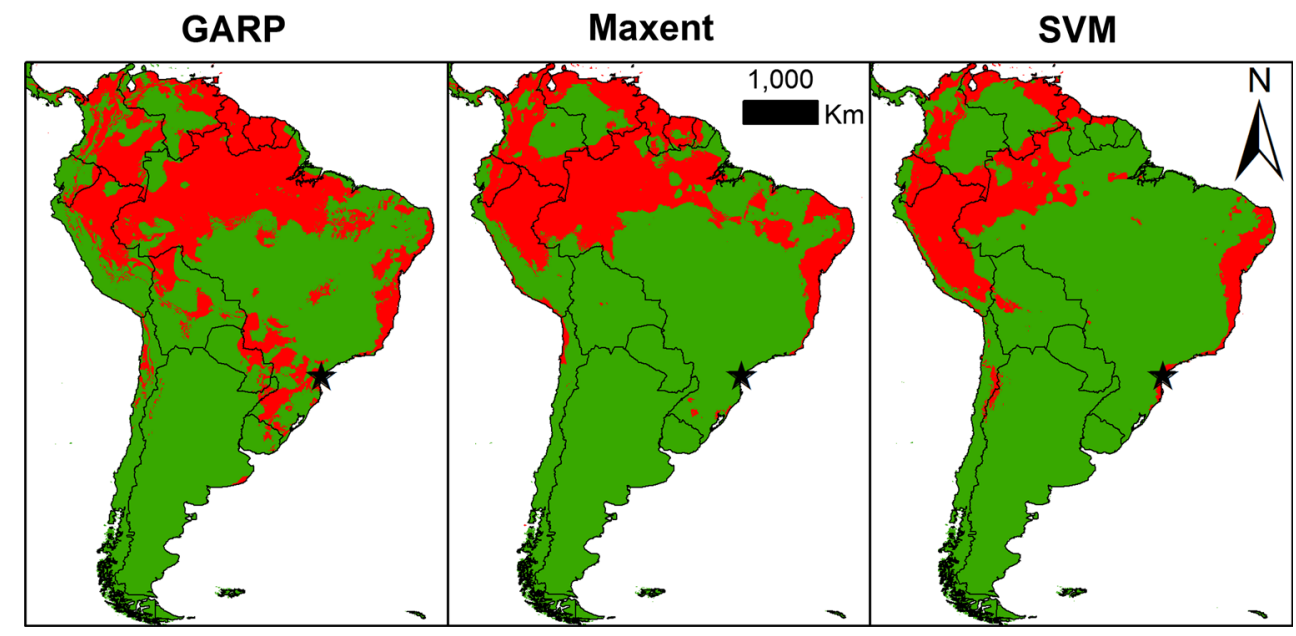

occurrences of a given species may increase its potential reachable area by several thousand square kilometers (e.g. Almeida et al. 2010; Silva et al. 2013). Availability of digital records of specimens by museums' curators should be continuously increased in order to ensure SDMs modelers are provided with precise data to predict the distribution of target species. Additionally, citizen science projects, such as Bug Guide (bugguide.net), but mainly Facebook entomology groups, should encourage their members to make their findings available to the scientific community in order to make the entomological diversity of poorly known Tropical regions to be better known. Citizen science projects elsewhere in the world are showing very interesting, promising, and updated information on the biodiversity from the countries where they are being developed (e.g. Hochachka et al. 2012; Lucky et al. 2014)
The predicted Amazonian-Atlantic distribution of $M$. cervicornis is another source of concern. In the past, both of these South American rainforest formations were connected before at least in three different periods, with the last one around $12 \mathrm{Kyrs}$ before present (De Oliveira et al. 1999). Later, after climatic conditions changed, they were separated by the open vegetation in the current diagonal dry corridor, a past climatic event that shaped the biological communities within both forests today (see Silva et al. 2014b for a brief review). Therefore, as observed for other insect species in both forest formations, the taxonomic entity currently denominated as M. cervicornis may represent cryptic species. This scenario is plausible due to the lack of consistent suitable areas for the dispersal of $M$. cervicornis from the Amazon to the Atlantic Forest and vice versa, except for some Brazilian northeastern regions.
Fig. 5 Conservation coverage of $M$. cervicornis considering the current system of South American reserves. The considered scenarios were $\mathbf{a}$ restrictive and $\mathbf{b}$ progressive. Black areas correspond to protected areas where $M$. cervicornis was predicted as present at least once in (a) or by all three algorithms in (b). (Color figure online)

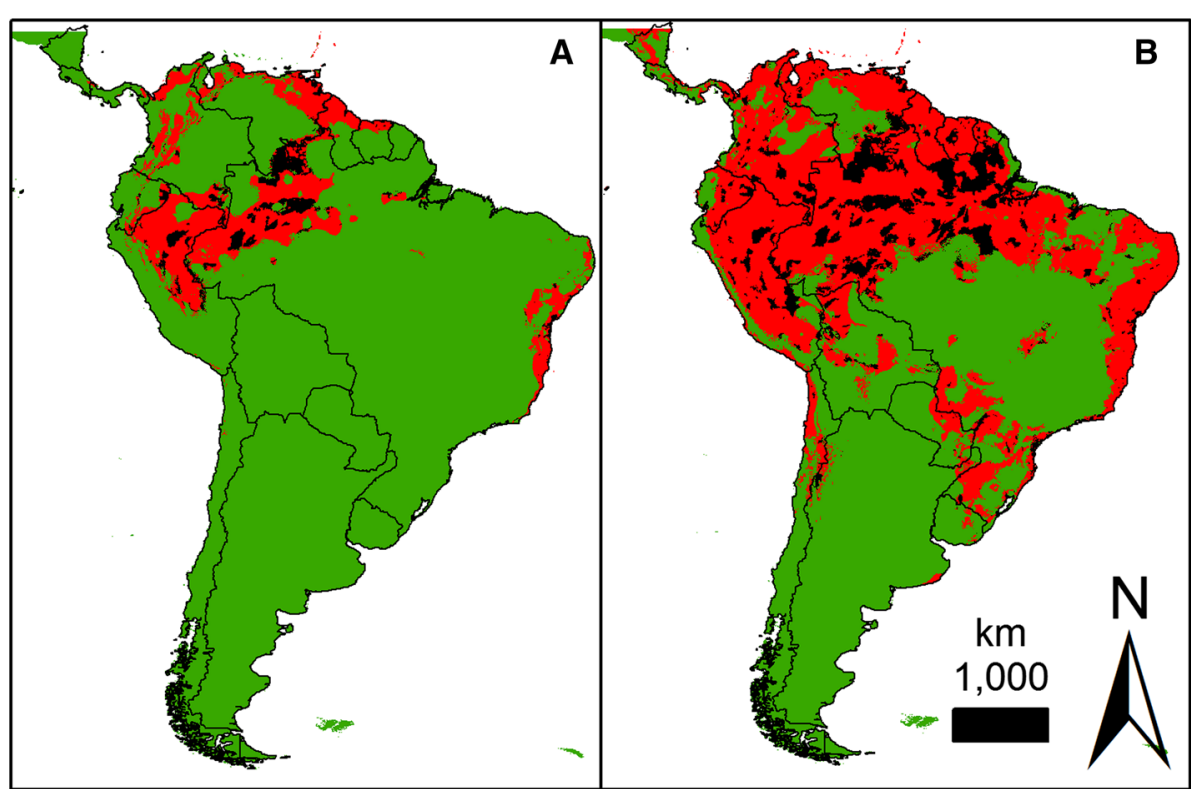


Therefore, specimens from both biomes should be revisited in order investigate this possibility, as already observed for other Amazonian-Atlantic related species pairs (de Vivo 1997; Costa 2003; Batalha-Filho et al. 2012; Silva et al. 2014b).

Although the SDMs may show a variety of results with contrasting patterns (Barry and Elith 2006; Diniz-Filho et al. 2009), the main results we obtained with different SDMs were congruent. Criticism of SDMs are related to the lack of biological reliability these methods may present, especially because much of the biological (e.g. perspectives related to demography, species interactions, and source-sink metapopulation dynamics) and biogeographic components of a given species' ecological niche are not properly covered by SDMs techniques (Soberón and Peterson 2005; Soberón 2007; Peterson et al. 2011; McInerny and Etienne 2012a, b, c).

The use of all available independent/unique occurrences for $M$. cervicornis as the input data to generate our models may be criticized, since SAC may have pervasive effects on the distribution models produced by any algorithm used in the field of species distribution modelling (Veloz 2009; Record et al. 2013; Diniz-Filho et al. 2016). On the other hand, $M$. cervicornis is a beetle species rarely sampled in South America, and for a first distribution prediction for this species, even single additional occurrences may cause important changes to the modelling results. For instance, Silva et al. (2013) showed that the inclusion of additional records for a rare Amazonian orchid bee sampled in the Cerrado into their SDMs caused significant changes to the obtained geographic predictions for this species, subsequently this species was found considerably further to the east of its historical distribution (Martins et al. 2016). In another study, Almeida et al. (2010) showed the impact of adding more occurrences to the distribution models of rare damselflies South American species, which were significantly underestimated before the discovery of these new occurrences. Therefore, we kept all unique occurrence records we could find in our results and advocate for the maintenance of all available occurrences for rare species in SDM studies.

Notwithstanding, given the conservation scenario considered here $(\sim 15 \%$ of its distribution is covered by protected areas) and assuming the species as being currently only one, we may consider that the species is protected. Still, the public concern about the human pressure and species conservation is an important topic among researchers, especially considering current rates of deforestation, downgrading, downsize, and functional loss of legal protection for an entire protected area (due to degazetting and downsizing) from the South American reserve system (Loyola 2014; Ferreira et al. 2014). In consequence, the potential impacts of human pressure on insect biodiversity (M. cervicornis included) need to be continually evaluated. For this purpose, SDMs are important tools that provide support for practical conservation actions, despite their methodological and theoretical limitations (Diniz-Filho et al. 2010; Cardoso et al. 2011; Guisan et al. 2013).

Given our results, we believe M. cervicornis is protected with regard to the available system of South American protected areas. Yet, a taxonomic review of this species is necessary to conclude adequate protection, since the occurrences in the Amazon and the Atlantic forest may represent (at least) two different species. Additionally, as new records of $M$. cervicornis are accumulated, new modeling procedures are required to (1) continuously assess M. cervicornis conservation status in South America, (2) shed light on the potential existence of cryptic species under the name of M. cervicornis, and (3) inform potential dispersal routes in South America for this species.

Acknowledgments We thank A. C. Martins, O. Gauthier, C. Phifer, E. Wendpap, and two anonymous reviewers for important improvements of a previous version of this manuscript. JSF is grateful to Universidade Estadual de Goiás for the grant support she received from the "Programa de Bolsa de Incentivo à Pesquisa" (PROBIP). In memoriam of Marcisnei L. Zimmermann, a promising professor and a good friend.

\section{References}

Ab'Saber AN (1977) Os domínios morfoclimáticos da América do Sul. Primeira Aproximação. Geomorfologia 52:1-21

Aguiar AJC, Melo GAR (2007) Taxonomic revision, phylogenetic analysis, and biogeography of the bee genus Tropidopedia (Hymenoptera, Apidae, Tapinotaspidini). Zool J Linn Soc 151:511-554

Allouche O, Tsoar A, Kadmon R (2006) Assessing the accuracy of species distribution models: prevalence, kappa and the True Skill Statistic (TSS). J Appl Ecol 43:1223-1232

Almeida MC, Côrtes LG, De Marco Jr P (2010) New records and a niche model for the distribution of two Neotropical damselflies: Schistolobos boliviensis and Tuberculobasis inversa (Odonata: Coenagrionidae). Insect Conserv Divers 3:252-256

Anderson RP, Gonzalez IJ (2011) Species-specific tuning increases robustness to sampling bias in models of species distributions: an implementation with Maxent. Ecol Model 222:2796-2811

Araújo MB, New M (2007) Ensemble forecasting of species distributions. Trends Ecol Evol 22:42-47

Barry S, Elith J (2006) Error and uncertainty in habitat models. J Appl Ecol 43:413-423

Batalha-Filho H, Fjeldså J, Fabre PH, Miyaki CY (2012) Connections between the Atlantic and the Amazonian forest avifaunas represent distinct historical events. J Ornithol 154:41-50

Bosso L, Rebelo H, Garonna AP, Russo D (2013) Modelling geographic distribution and detecting conservation gaps in Italy for the threatened beetle Rosalia alpina. J Nat Conserv 21:72-80. doi:10.1016/j.jnc.2012.10.003

Brooks TM, Mittermeier RA, da Fonseca GAB et al (2006) Global biodiversity conservation priorities. Science 313:58-61

Brown KS Jr (1987) Biogeography and evolution of Neotropical butterflies. In: Whitmore T, Prance G (eds) Biogeography and 
quaternary history in tropical America. Oxford University Press, Oxford, pp 66-104

Brown KS Jr (1992) Habitat alteration and species loss in Brazilian forests. In: Whitmore T, Sayer J (eds) Tropical deforestation and species extinction. Chapman and Hall, London, pp 119-142

Cardoso P, Erwin TL, Borges PAV, New TR (2011) The seven impediments in invertebrate conservation and how to overcome them. Biol Conserv 144:2647-2655

Cavalli M, Baladrón AV, Isacch JP et al (2014) Social networks and ornithology studies: an innovative method for rapidly accessing data on conspicuous bird species. Biodivers Conserv 23:2127-2134. doi:10.1007/s10531-014-0704-8

Chown SL, Terblanche JS (2006) Physiological diversity in insects: ecological and evolutionary contexts. Adv In Insect Phys $33: 50-152$

Costa LP (2003) The historical bridge between the Amazon and the Atlantic Forest of Brazil: a study of molecular phylogeography with small mammals. J Biogeogr 30:71-86

Da Mata RA, Tidon R, Côrtes LG et al (2010) Invasive and flexible: niche shift in the drosophilid Zaprionus indianus (Insecta, Diptera). Biol Invasions 12:1231-1241

De Oliveira PE, Magno A, Suguio K (1999) Late Pleistocene/ Holocene climatic and vegetational history of the Brazilian Caatinga: the fossil dunes of the middle São Francisco River. Palaeogeogr Palaeoclimatol Palaeoecol 152:319-337

de Oliveira G, Rangel TF, Lima-Ribeiro MS et al (2014) Evaluating, partitioning, and mapping the spatial autocorrelation component in ecological niche modeling: a new approach based on environmentally equidistant records. Ecography 37:637-647

de Vivo M (1997) Mammalian evidence of historical ecological change in the Caatinga semiarid vegetation of northeastern Brazil. J Comp Biol 2:65-73

Diniz-Filho JAF, Bini LM, Rangel TFLVB et al (2009) Partitioning and mapping uncertainties in ensembles of forecasts of species turnover under climate change. Ecography 32:897-906

Diniz-Filho JAF, De Marco Jr P, Hawkins BA (2010) Defying the curse of ignorance: perspectives in insect macroecology and conservation biogeography. Insect Conserv Divers 3:172-179

Diniz-Filho JAF, Loyola RD, Raia P et al (2013) Darwinian shortfalls in biodiversity conservation. Trends Ecol Evol 28:689-695

Diniz-Filho JAF, Barbosa ACOF, Collevatti RG et al (2016) Spatial autocorrelation analysis and ecological niche modelling allows inference of range dynamics driving the population genetic structure of a Neotropical savanna tree. J Biogeogr 43:167-177. doi:10.1111/jbi.12622

Dirzo R, Young HS, Galetti M et al (2014) Defaunation in the Anthropocene. Science 345:401-406

Doko T, Fukui H, Kooiman A et al (2011) Identifying habitat patches and potential ecological corridors for remnant Asiatic black bear (Ursus thibetanus japonicus) populations in Japan. Ecol Model 222:748-761. doi:10.1016/j.ecolmodel.2010.11.005

Duan R-Y, Kong X-Q, Huang M-Y et al (2014) The predictive performance and stability of six species distribution models. PLoS ONE 9:e112764

Elith J, Graham CH, Anderson RP et al (2006) Novel methods improve prediction of species' distributions from occurrence data. Ecography 29:129-151

Elith J, Phillips SJ, Hastie T et al (2011) A statistical explanation of MaxEnt for ecologists. Divers Distrib 17:43-57

Escalante JA (1973) Apuntes sobre insectos del Alto Urubamba, Cusco. Rev Peru Entomol 17:120-121

Ferreira J, Aragão LEOC, Barlow J et al (2014) Brazil's environmental leadership at risk. Science 346:706-707

Ferro VG, Lemes P, Melo AS, Loyola R (2014) The reduced effectiveness of protected areas under climate change threatens Atlantic Forest tiger moths. PLoS ONE 9:e107792
Giannini TC, Acosta AL, Garófalo CA et al (2012) Pollination services at risk: bee habitats will decrease owing to climate change in Brazil. Ecol Model 244:127-131

Google Inc. (2015) Google Earth, version 7.0.3.8542

Graham CH, Ferrier S, Huettman F et al (2004) New developments in museum-based informatics and applications in biodiversity analysis. Trends Ecol Evol 19:497-503

Guisan A, Tingley R, Baumgartner JB et al (2013) Predicting species distributions for conservation decisions. Ecol Lett 16:1424-1435

Hernandez PA, Graham CH, Master LL, Albert DL (2006) The effect of sample size and species characteristics on performance of different species distribution modeling methods. Ecography 29:773-785

Hijmans RJ, Cameron SE, Parra JL et al (2005) Very high resolution interpolated climate surfaces for global land areas. Int J Climatol 25:1965-1978

Hochachka WM, Fink D, Hutchinson RA et al (2012) Data-intensive science applied to broad-scale citizen science. Trends Ecol Evol 27:130-137. doi:10.1016/j.tree.2011.11.006

Hortal J, de Bello F, Diniz-Filho JAF et al (2015) Seven shortfalls that beset large-scale knowledge of biodiversity. Annu Rev Ecol Evol Syst 46:523-549. doi:10.1146/annurev-ecolsys-112414054400

IUCN (2006) IUCN red list of threatened species. www.iucnredlist. org. Accessed 28 Nov 2014

Jiménez-Valverde A, Peterson AT, Soberón J et al (2011) Use of niche models in invasive species risk assessments. Biol Invasions 13:2785-2797

Kramer-Schadt S, Niedballa J, Pilgrim JD et al (2013) The importance of correcting for sampling bias in MaxEnt species distribution models. Divers Distrib 19:1366-1379

Liu CR, Berry PM, Dawson TP, Pearson RG (2005) Selecting thresholds of occurrence in the prediction of species distributions. Ecography 28:385-393

Liu C, White M, Newell G (2011) Measuring and comparing the accuracy of species distribution models with presence-absence data. Ecography 34:232-243

Losey JE, Vaughan M (2006) The economic value of ecological services provided by insects. Bioscience $56: 311$

Loyola R (2014) Brazil cannot risk its environmental leadership. Divers Distrib. doi:10.1111/ddi.12252

Lucky A, Savage AM, Nichols LM, et al (2014) Ecologists, educators, and writers collaborate with the public to assess backyard diversity in The School of Ants Project. Ecosphere 5: art78. doi: 10.1890/ES13-00364.1

Martins UR, Galileo MHM, Limeira-de-Oliveira F (2009) Cerambycidae (Coleoptera) do estado do Maranhão, Brasil. Papéis Avulsos Zool do Mus Zool da Univ São Paulo 49:229-247

Martins AC, Silva DP, De Marco Jr P, Melo GAR (2015) Species conservation under future climate change: the case of Bombus bellicosus, a potentially threatened South American bumblebee species. J Insect Conserv 19:33-43

Martins DC, Albuquerque PMC, Silva FS, Rebêlo JMM (2016) First record of Aglae caerulea (Hymenoptera, Apidae, Euglossini) in Brazilian Cerrado east of the Amazon Region, Maranhão State, Brazil. Rev Bras Biol 76:554-556. doi:10.1590/1519-6984. 06415

McInerny GJ, Etienne RS (2012a) Ditch the niche-is the niche a useful concept in ecology or species distribution modelling? J Biogeogr 39:2096-2102

McInerny GJ, Etienne RS (2012b) Stitch the niche-a practical philosophy and visual schematic for the niche concept. J Biogeogr 39:2103-2111

McInerny GJ, Etienne RS (2012c) Pitch the niche-taking responsibility for the concepts we use in ecology and species distribution modelling. J Biogeogr 39:2112-2118 
Méio BB, Freitas CV, Jatobá L et al (2003) Influência da flora das florestas Amazônica e Atlântica na vegetação do cerrado sensu stricto. Rev Bras Botânica 26:437-444

Menezes EC, Silva-Neto AM, Nascimento FEL, Bravo FR (2012) Lista das espécies da família Cerambicydae, incluindo 12 holótipos, presentes na coleção entomológica Professor Johann Becker do Museu de Zoologia da Universidade Estadual de Feira de Santana (MZUEFS) e o primeiro registro da espécie Chrysoprasis airi. Entomobrasilis 5:49-58

Miller JA (2012) Species distribution models: spatial autocorrelation and non-stationarity. Prog Phys Geogr 36:681-692

Mittermeier R, Baião PC, Barrera L et al (2010) Brazil's leading role in the historical global agreement for the protection of biodiversity. Nat Conserv 8:197-200

Mora C, Tittensor DP, Adl S et al (2011) How many species are there on Earth and in the ocean? PLoS Biol 9:e1001127

Muñoz MES, De Giovanni R, de Siqueira MF et al (2011) openModeller: a generic approach to species' potential distribution modelling. Geoinformatica 15:111-135

Myers N, Mittermeier RA, Mittermeier CG et al (2000) Biodiversity hotspots for conservation priorities. Nature 403:853-858

Newbold T (2010) Applications and limitations of museum data for conservation and ecology, with particular attention to species distribution models. Prog Phys Geogr 34:3-22

Nóbrega CC, De Marco Jr P (2011) Unprotecting the rare species: a niche-based gap analysis for odonates in a core Cerrado area. Divers Distrib 17:491-505

Pearson RG, Raxworthy CJ, Nakamura M, Peterson AT (2007) Predicting species distributions from small numbers of occurrence records: a test case using cryptic geckos in Madagascar. J Biogeogr 34:102-117

Peterson AT, Soberón J, Pearson RG et al (2011) Ecological niches and geographic distributions, 1st edn. Princeton University Press, Princeton

Phillips SJ, Dudík M (2008) Modeling of species distributions with Maxent: new extensions and a comprehensive evaluation. Ecography 31:161-175

Phillips SJ, Anderson RP, Schapire RE (2006) Maximum entropy modeling of species geographic distributions. Ecol Model 190:231-259

Pyke GH, Ehrlich PR (2010) Biological collections and ecological/ environmental research: a review, some observations and a look to the future. Biol Rev 85:247-266

Rangel TF, Loyola RD (2012) Labeling ecological niche models. Nat Conserv 10:119-126

Record S, Fitzpatrick MC, Finley AO et al (2013) Should species distribution models account for spatial autocorrelation? A test of model projections across eight millennia of climate change. Glob Ecol Biogeogr 22:760-771

Redford KH, da Fonseca GAB (1986) The role of gallery forests in the zoogeography of the Cerrado's non-volant mammalian fauna. Biotropica 18:126-135

Rocchini D, Hortal J, Lengyel S et al (2011) Accounting for uncertainty when mapping species distributions: the need for maps of ignorance. Prog Phys Geogr 35:211-226

Rodrigues ASL, Andelman SJ, Bakarr MI et al (2004) Effectiveness of the global protected area network in representing species diversity. Nature 428:640-643

Russo D, Di Febbraro M, Rebelo H et al (2014) What story does geographic separation of insular bats tell? A case study on Sardinian rhinolophids. PLoS ONE 9:e110894. doi:10.1371/ journal.pone.0110894

Russo D, Di Febbraro M, Cistrone L et al (2015) Protecting one, protecting both? Scale-dependent ecological differences in two species using dead trees, the rosalia longicorn beetle and the barbastelle bat. J Zool 297:165-175. doi:10.1111/jzo.12271

Salazar JA (2008) Sobre algunas localidades colombianas para conocer y estudiar Macrodontia cervicornis (L.), M. dejeani (Gory) y Titanus giganteus (L.) (Coleoptera: Cerambycidae). Bol Mus Hist Nat 8:155-171

Sampaio EVSB (1995) Overview of the Brazilian Caatinga. In: Bullock SH, Mooney HA, Medina E (eds) Seasonally tropical dry forests, 1st edn. Cambridge University Press, Cambridge

Schölkopf B, Platt JC, Shawe-Taylor J et al (2001) Estimating the support of a high-dimensional distribution. Neural Comput 13:1443-1471

Serra BDV, De Marco Jr P, Nóbrega CC, Campos LAO (2012) Modeling potential geographical distribution of the wild nests of Melipona capixaba Moure \& Camargo, 1994 (Hymenoptera, Apidae): conserving isolated populations in mountain habitats. Nat Conserv 10:199-206

Silva JMC (1996) Distribution of Amazonian and Atlantic birds in gallery forests of the Cerrado region, South America. Ornitol Neotrop 7:1-18

Silva DP, Aguiar AJC, Melo GAR et al (2013) Amazonian species within the Cerrado savanna: new records and potential distribution for Aglae caerulea (Apidae: Euglossini). Apidologie 44:673-683

Silva DP, Gonzalez VH, Melo GAR et al (2014a) Seeking the flowers for the bees: integrating biotic interactions into niche models to assess the distribution of the exotic bee species Lithurgus huberi in South America. Ecol Model 273:200-209

Silva DP, Vilela B, De Marco Jr P, Nemésio A (2014b) Using ecological niche models and niche analyses to understand speciation patterns: the case of sister neotropical orchid bees. PLoS ONE 9:e113246

Soberón J (2007) Grinnellian and Eltonian niches and geographic distributions of species. Ecol Lett 10:1115-1123

Soberón J, Peterson AT (2005) Interpretation of models of fundamental ecological niches and species' distributional areas. Biodivers Informatics 2:1-10

Souza RA, De Marco Jr P (2014) The use of species distribution models to predict the spatial distribution of deforestation in the western Brazilian Amazon. Ecol Model. doi:10.1016/j.ecolmo del.2014.07.007

Stockwell D, Peters D (1999) The GARP modelling system: problems and solutions to automated spatial prediction. Int J Geogr Inf Sci 13:143-158

Tax DMJ, Duin RPW (2004) Support vector data description. Mach Learn 54:45-66

Varela S, Anderson RP, García-Valdés R, Fernández-González F (2014) Environmental filters reduce the effects of sampling bias and improve predictions of ecological niche models. Ecography 37:1084-1091

Veloso HP, Rangel-Filho ALR, Lima JCA (1991) Classificação da vegetação brasileira, adaptada a um sistema universal, 1st edn. Instituto Brasileiro de Geografia e Estatística-IBGE, Rio de Janeiro

Veloz SD (2009) Spatially autocorrelated sampling falsely inflates measures of accuracy for presence-only niche models. J Biogeogr 36:2290-2299

Virkkala R, Heikkinen RK, Fronzek S, Leikola N (2013) Climate change, northern birds of conservation concern and matching the hotspots of habitat suitability with the reserve network. PLoS ONE 8:e63376. doi:10.1371/journal.pone.0063376

Whittaker RJ, Araújo MB, Jepson P et al (2005) Conservation biogeography: assessment and prospect. Divers Distrib 11:3-23

Wilson EO (1987) The little things that run the world (the importance and conservation of invertebrates). Conserv Biol 1:344-346 